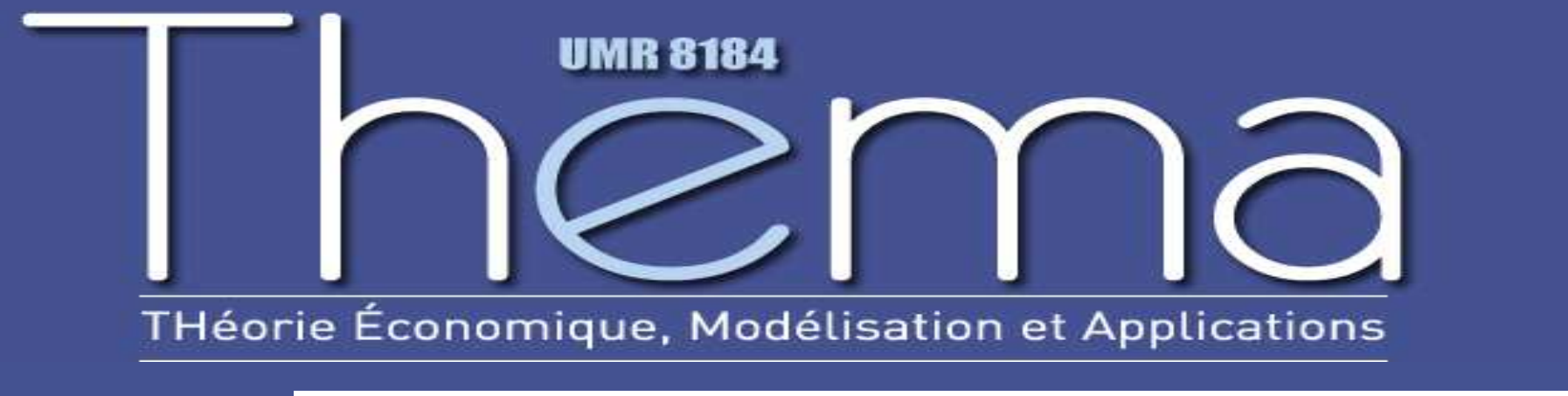

THEMA Working Paper n²017-16 Université de Cergy-Pontoise, France

\title{
Intellectual Property Rights, Multinational Firms and Technology Transfers
}

Sara Biancini, Pamela Bombarda 


\title{
Intellectual Property Rights, Multinational Firms and Technology Transfers*
}

\author{
Sara Biancini ${ }^{\dagger}$ and Pamela Bombarda ${ }^{\ddagger}$
}

July 17, 2017

\begin{abstract}
Intellectual property rights (IPR) protect firms from imitation and are considered crucial to promote innovation and technological diffusion. This paper examines the impact of IPR on import sourcing decisions of multinationals. We consider a framework in which multinational firms offshore production of an intermediate good in a developing country. Firms can either decide to import the intermediate from vertically integrated producers, or from independent suppliers. In both cases, offshoring part of the production process embodies a risk of imitation. The model predicts that, under reasonable assumptions, stronger IPR encourage by a larger extent the imports of intermediates through vertical integration. Using U.S. Related-Party Trade database, we find empirical evidence supportive of the positive link between level of IPR and the relative share of imports from vertically integrated manufacturers.
\end{abstract}

JEL classification: F23, F12.

Keywords: Intellectual Property Rights, MNF, FDI, outsourcing, international trade.

*Acknowledgements: We would like to thank Carlo Altomonte, Lionel Fontagné, Alireza Naghavi, Rodrigo Paillacar, Ariell Reshef and Régis Renault for helpful comments and suggestions. Remarks from participants at the 2016 ETSG Workshop, the CES-Ifo Workshop in Applied Microeconomics and seminars at THEMA-Cergy and Paris 1 contributed to improve this paper. All errors are ours.

${ }^{\dagger}$ Université de Caen Normandie, CREM, sara.biancini@unicaen.fr.

‡Université de Cergy-Pontoise, THEMA, pamela.bombarda@u-cergy.fr. 


\section{Introduction}

Anecdotal and empirical evidence stress the importance of intellectual property protection for international trade and technology transfers, especially in developing countries. Weak intellectual property rights (henceforth IPR) can harm outsourcing contracts, because outsourcing requires some transfer of technology (see Yang and Maskus, 2001). Therefore, multinational firms (henceforth MNF) could be exposed to a higher risk of technology expropriation. However, a similar expropriation risk can occur when technology transfers happen within firm's boundaries. Maskus et al. (2005) report anecdotal evidence for China showing that firms lose technologies to potential rivals through "the defection of technical personnel, misappropriation by input suppliers, copying of blueprints". From their interviews, it appears that former licensees and employees sometimes end up running their own factories, producing their version of the goods formerly introduced by foreign multinationals and infringing the related trademarks and patents. This example suggests that vertical integration can yield a risk of expropriation through the imitation of the technology developed by multinational firms. For this reason, weak intellectual property rights in the destination country can discourage intra-firm trade, and the associated technological transfers. Figure 1 provides an illustration of the relation between IPR and the share of intra-firm imports on total imports made by U.S. multinationals. Each point represents a bilateral relation between U.S. and the destination country. The vertical axis measures the average share of intra-firm imports from each destination country; the horizontal axis measures the average IPR level in each destination country. The higher is the level of IPR in the destination country, the higher the share of U.S. intra-firm imports in total U. S. imports.

Figure 1: Share of Intra Firms Import

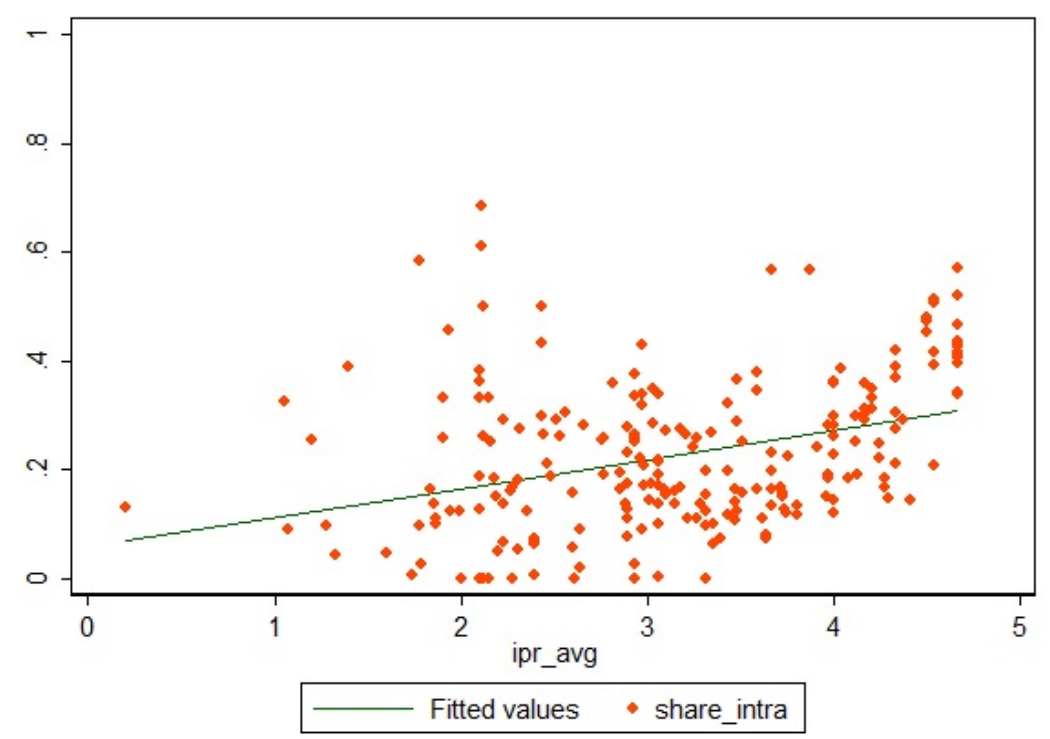

Source: Authors' calculation using U.S. Input-Output tables and IPR averaged 2000-2005. 
The present paper provides theoretical and empirical support to the idea that stronger IPR might encourage by a larger extent the propensity to engage in vertical integration compared to outsourcing. The theoretical framework follows Antràs (2003) and Antràs and Helpman (2004) in embedding the property rights approach in a global value chains context. We consider multinational firms based in a developed country, the North, which offshore production of an intermediate good in a developing country, the South. When the MNF engages in vertical integration, it imports the intermediate from a foreign subsidiary. And when it engages in outsourcing, it imports from an independent contractor. Since vertical integration ensures the control of the physical capital, it shapes the contractual relationship in favor of the MNF. Departing from Antràs (2003) and Antràs and Helpman (2004), we assume that production in the South entails a risk of imitation. More specifically, when IPR are not well protected, the Southern manufacturer can operate the technology on the side, using the acquired Northern technology. We assume that this can occur with both vertical integration and outsourcing. But crucially, the firm's payoffs are affected differently depending on the chosen ownership structure. Although vertical integration guarantees control on the production facilities, the existence of an imitation risk reduces the advantage of ownership. In line with some empirical findings, which shows that the transfer of knowledge within the boundaries of the firm is particularly important, we claim that the risk of imitation is more severe with vertical integration.

Our model shows that, for both ownership modes, stronger IPR increase the profitability of the firm. This is coherent with the idea that the risk of imitation exists when dealing with an independent provider but also with a foreign affiliate. Additionally, the model shows that, in many reasonable cases, higher IPR support relatively more vertical integration. This happens because an increase in IPR restores the advantages of vertical integration in the bargaining problem, reinforcing the MNF's control over both physical capital and intangible assets. This implies that, strengthening IPR in the South increases the relative share of intra-firm imports, and decrease the share of imports from independent suppliers. Our model delivers this result when the Southern manufacturer can imitate the technology more easily under vertical integration than under outsourcing. This happens because vertical integration induces larger knowledge spillovers.

To empirically examine the role of IPR in affecting the global sourcing decisions of firms, we combine the index of patent protection in Park (2008) with data on US intra-firm trade taken from the U.S. Census Bureau's Related Party Trade Database. ${ }^{1}$ Our baseline empirical specification considers the impact of an increase in IPR protection on the share of related party intermediate imports, controlling for industry and country characteristics. We find a positive and statistically significant impact of IPR, which supports the theoretical finding that an increase in IPR protection is more valuable for vertical integrated firms. Then we assess the sensitivity and robustness of our results. First, we switch from the 2002 InputOutput industry codes to NAICS six digit industry classification, to include time varying industry variables. Then, we explore the role of differences in industry-level sensitivity to

\footnotetext{
${ }^{1}$ The US dataset is made available by Pol Antràs: http://scholar.harvard.edu/antras/books.
} 
IPR, showing that the impact of IPR protection is enhanced in patent-sensitive industries. Finally, we address possible endogeneity concerns using a two-stage instrumental variable approach. All specifications confirm the main finding that an increase in IPR protection increases the relative share of intra-firm imports.

Our work is related to different strands of the international trade literature. First, to the well-developed literature studying the theoretical and empirical determinants of vertical integration versus outsourcing, which builds on Antràs (2003) and Antràs and Helpman (2004), and it is summarized in Antràs (2015) . In this literature contract incompleteness is associated to the existence of weak property rights. Differently, in our paper, we characterize a specific role for IPR, by stressing the importance of intangibles and knowledge spillovers in shaping global sourcing decisions. This generates a separate channel through which IPR affects the internalization decision of multinational firms.

Second, our work relates to the literature that studies the impact of IPR on export, licensing and FDI. Different papers, linking IPR to trade, find a positive effect of an increase in IPR protection on bilateral trade flows (Maskus and Penubarti, 1995, Smith, 1999, Ivus, 2010). Other papers focus on the impact of IPR on licensing activity, highlighting a positive effect (see Yang and Maskus, 2001 and Park and Douglas Lippoldt, 2005 among others). None of these studies consider explicitly the relationship between IPR and the global sourcing decisions. More related to our study is Javorcik (2004a), which empirically studies the gains from stronger IPR. Using firm-level data set from Eastern Europe and the former Soviet Union, she finds that weak IPR deter foreign investment in high technology sectors where intellectual property rights play an important role. Differently from Javorcik (2004a), we analyze, theoretically and empirically, the effects of IPR on both FDI and outsourcing decisions. In our empirical exercise, we confirm some of her findings. In particular, we show that the effect of IPR differs depending on the patent-sensitivity of the industry. More recently, Naghavi et al. (2015) find that IPR protection does not affect the average outsourcing share of French multinational firms, but it affects the complexity of the outsourced input. In their framework, more complex tasks mitigate the need for IPR because they are difficult to imitate: as a result, the share of outsourcing of complex inputs tends to be smaller in countries with stronger IPR. ${ }^{2}$ Differently from them, we assume that hold-up and imitation problems can also emerge under vertical integration, and not exclusively in the case of outsourcing. We illustrate this point adopting a theoretical framework based on the property rights approach to contract incompleteness. Our set-up allows us to identify and then test empirically a different channel though which IPR can impact the value-chain structure. Since in our model the imitation threat differs between the two ownership structures, we find that IPR might have a stronger impact on vertical integration.

Finally, our paper relates to the literature on knowledge transfers and spillovers across global value chains. Javorcik (2004b) uses firm-level data from Lithuania to study vertical spillovers. She finds positive productivity spillovers from FDI taking place through contacts

\footnotetext{
${ }^{2}$ Ivus et al. (2016), concentrating on the technology licensing decisions of multinationals, identify a similar role of product complexity for U.S. multinationals.
} 
between foreign affiliates and their local suppliers in upstream sectors. Javorcik and Spatareanu (2009) study how firms become MNF's suppliers and how this interaction enhances supplier performance. To capture the relationships between suppliers and multinationals, they use Czech Republic data and find that independent suppliers tend to learn from multinational firms and be more productive than non-suppliers. Borrowing from these empirical findings, we build a model where independent manufacturers can learn the technology, and possibly become an imitator. Crucially, we claim that transfers of knowledge also occur under vertical integration and that these transfers are likely to be large inside vertically related groups. The idea that vertical integration facilitates knowledge transfer is empirically supported. Blomström and Sjöholm (1999), studying Indonesian manufacturing, show that ownership matters when considering the knowledge revealed by multinational firms. Branstetter (2006) shows that Japanese FDI into the United States are a channel of knowledge transfers both from and to investing firms, because they create spillovers at the firm level. More recently, Lee et al. (2016) use Korean data to compare the knowledge spillovers arising from networks of related firms with the ones arising from arm's length relationships. They conclude that knowledge is better transferred within business groups. Finally, Görg and Strobl (2005) highlight worker mobility as a channel through which knowledge transfer may occur: workers can join or open up a domestic firm taking with them the knowledge of the multinational. Although the threat of imitation is likely to affect both vertical integration and outsourcing, the findings in Lee et al. (2016) and Görg and Strobl (2005) seem to support our claim that this threat is particularly important under vertical integration.

The paper is structured as follows. Section 2 proposes the theoretical framework. Section 3 characterizes the different organizational forms. Section 4 describes the industry's equilibrium and derives the prediction to be tested. Section 5 describes the empirical strategy. The estimation results and robustness checks are discussed in Sections 6. Finally, Section 7 concludes.

\section{The model}

We adopt a monopolistic competition framework in line with Antràs and Helpman (2004). The world consists of two countries, North and South, and one factor of production, labor. Consumers have identical Dixit-Stiglitz preferences represented by:

$$
U=x_{0}+\frac{1}{\mu} \sum_{j=1}^{J} X_{j}^{\mu}, \quad 0<\mu<1,
$$

where $x_{0}$ is a homogeneous good, $X_{j}$ is aggregate consumption in sector $j$, and $\mu$ is a parameter. World aggregate consumption in sector $j$ of different varieties $x_{j}(i)$ is given by:

$$
X_{j}=\left[\int x_{j}(i)^{\alpha} \mathrm{d} i\right]^{\frac{1}{\alpha}}, \quad 0<\alpha<1
$$


where $i$ is the endogenous range of varieties in sector $j$, and $1 /(1-\alpha)$ is the elasticity of substitution between two varieties. As a consequence, the inverse demand for each variety writes:

$$
p_{j}=A_{j} x_{j}(i)^{\alpha-1}, \quad 0<\alpha<1,
$$

where $A_{j}=X_{j}^{\mu-\alpha}$. We set $\alpha>\mu$ so that varieties within a sector are more substitutable for each other than they are for varieties from a different sector. Parameters $\mu$ and $\alpha$ are the same in every industry. Each variety is produced by a monopolistically-competitive firm under increasing returns to scale.

Producers in the differentiated sector face a perfectly elastic labor supply in each country. Wage rates are consider fixed, with the wage rate in the North, $w_{N}$, larger than wage rate in the South, $w_{S}$. New varieties can only be invented in the North. To start producing a new variety, the Northern multinational firm has to bear a fixed cost $f_{E}$ paid in unit of Northern labor. After paying this fixed cost, a firm-specific productivity parameter $\theta$ is drawn from a known distribution $G(\theta)$. Production of the final-good variety requires the combination of two factors, $z_{j}(i)$ and $m_{j}(i)$, which represent headquarter services and manufacturing inputs respectively. The production of the final good variety combines two intermediate inputs into a Cobb-Douglas function:

$$
x_{j}=\theta\left[\frac{z_{j}(i)}{\eta_{j}}\right]^{\eta_{j}}\left[\frac{m_{j}(i)}{1-\eta_{j}}\right]^{1-\eta_{j}}, \quad 0<\eta_{j}<1,
$$

where $\theta$ is the firm-specific productivity parameter, and $\eta_{j}$ is sector specific and it indicates sector intensity in headquarter services. Both intermediates $z_{j}(i)$ and $m_{j}(i)$ are produced using one unit of labour. The headquarter services, $z_{j}(i)$, can only be produced in the North, wheras the manufacturing input, $m_{j}(i)$, is produced only in the South. ${ }^{3}$ As in Antràs and Helpman (2004), there are two types of agents involved in production: final good producers, who also supply the headquarter services, and producers of the manufacturing inputs. The final good producer needs to stipulate a contract with a Southern manufacturing input supplier. ${ }^{4}$ The fragmentation of the production process can take two forms: vertical integration or outsourcing. When the final good producer imports the intermediate $m_{j}(i)$ from a foreign affiliate, it engages in vertical integration. Differently, when the imports come from an independent manufacturer, it engages in outsourcing. In both cases the intermediate goods are shipped back to the North where final assembling takes place. Intermediate production in the South requires the transfer of technological knowledge from the Northern MNF. This transfer differs depending on the ownership structure.

We follow Antràs and Helpman (2004), and argue that managerial overload is more important than managerial economies of scope. This allows us to adopt a particular ranking for

\footnotetext{
${ }^{3}$ Alternatively, we could assume that $m_{j}(i)$ could be produced either in the North or in the South, with production in the North entailing a higher fixed cost. This would not alter our main results, which concentrate on the relative profitability of vertical integration and outsourcing in the South.

${ }^{4}$ Since the final good producer is a MNF, in the paper we use final good producer and MNF interchangeably.
} 
the fixed cost. Specifically, we assume that the fixed organizational costs are higher under vertical integration than under outsourcing:

$$
f_{V}>f_{O}
$$

where the subscripts $V$ and $O$ indicate vertical integration and outsourcing respectively. The final good producer chooses ex-ante the ownership structure. In case of outsourcing, the final good producer offers a contract to the manufacturer in exchange for an upfront fixed fee.

Focusing on one industry, we can drop the subscript $j$. Replacing (1) and (2) into the revenue expression yields:

$$
R=A x(i)^{\alpha}=A \theta^{\alpha}\left[\frac{z(i)}{\eta}\right]^{\alpha \eta}\left[\frac{m(i)}{\alpha(1-\eta)}\right]^{\alpha(1-\eta)},
$$

Equation (4) represents the final good producer's revenue in the absence of contractual breach. The next section describes the incomplete contract problem, allowing for ex-post bargaining and for the possibility that the Southern manufacturer decides to breach the contract, imitate the technology and compete against the final good producer.

\section{The Incomplete Contracts Problem}

We follow Antràs and Helpman (2004) assuming that under both vertical integration and outsourcing, contracts are totally incomplete. This implies that parties cannot commit ex-ante to a certain distribution of the surplus. The assumption of incomplete contracts follows the property right approach, which introduces the hold up problem also for vertically integrated structures (Grossman and Hart, 1986). We denote $\beta$ and $1-\beta$, with $\beta \in[0,1]$, the bargaining weights of the final good producer and the South manufacturer respectively. Both vertical integration and outsourcing feature an ex-ante contracting stage $t_{0}$, an investment stage $t_{1}$, and an ex-post bargaining stage $t_{2}$. At $t_{2}$, the outside options available to the final good producer and the manufacturer are a function of the ownership decision at $t_{0}$.

Departing from the existent literature, we assume that, in the South, IPR are protected only with some probability $\lambda \in(0,1)$, where $\lambda$ represents the strength of this protection. The higher is $\lambda$, the higher is the probability that MNF are protected from the risk of imitation and technological expropriation. Specifically, in our model, the Southern manufacturer can learn the technology developed by the Northern MNF and become and imitator. The threat of imitation becomes effective when IPR are not sufficiently protected. In this case, the Southern manufacturer can free ride the Northern technology, and possibly replicate the good infringing the MNF's property rights. Therefore, a decrease in $\lambda$ increases the outside option of the manufacturer. On the contrary, the higher is $\lambda$, the higher the probability that IPR are protected against imitation. This increases the MNF's outside option.

In our setup, the protection of intellectual property rights matters both under outsourcing and vertical integration. In both cases, the Southern manufacturer can free ride on the final 
good producer's technology and become an imitator. We assume that $\lambda$ is independent on the offshoring mode, which implies that outsourcing and vertical integration have the same $\lambda$. But crucially, we claim that the ability to imitate is larger with vertical integration. In the model this happens because vertical integration induces higher knowledge spillovers, which facilitates imitation. For simplicity, we do not consider the risk of technological expropriation coming from imitators external to the relationship between the final good producer and the manufacturer. This choice should not alter our results. The existence of multiple imitators, by reducing the demand for the differentiated, would have a scale effect, without altering qualitatively our results.

Let's now describe what happens after a contractual breach. In this case, the role of $\lambda$ is crucial. If $\lambda$ is low, the manufacturer can exploit the learned technology and replicate the production technique of the MNF. More precisely, we assume that the Southern manufacturer, by paying a smaller fixed cost, can realize a copy of the good produced by the multinational. In our framework, a contractual breach implies a loss in efficiency for both agents in each ownership structure. Similarly to Antràs and Helpman (2004), the MNF is able to assemble only a share $\delta^{H} \in(0,1)$ of the output $x_{i}$. But in addition, we assume that the manufacturer, when operating the technology on the side, can also realize a share $\varphi_{k}^{M} \in(0,1)$ of the potential output, where $k \in\{V, O\}$. This share depends on the manufacturer's ability to imitate the foreign technology: if under vertical integration technological spillovers are higher, then this share will be higher, i.e. $\varphi_{V}^{M}>\varphi_{O}^{M}{ }^{5}$ In the following sections, we characterize profits and outside options both under integration and under outsourcing.

\subsection{Vertical Integration}

When the organizational form is vertical integration, the MNF has the ability to fire the manufacturer if he refuses to agree on a transfer price, and find an alternative way to assemble the final good. This happens because the MNF holds property rights over the inputs. In our framework, the fraction of the total revenue that the MNF is able to realize depends crucially on the enforcement of intellectual property rights. If IPR are enforced, which occurs with probability $\lambda$, firing the manufacturer only results in a loss of a fraction of the final-good production. This happen because the MNF cannot use the intermediate inputs as effectively as with the cooperation. In this scenario, the MNF's revenue equals to $A \delta^{H^{\alpha}} x_{i}^{\alpha}=\delta R$, with $\delta^{H^{\alpha}} \equiv \delta<1$. Differently, if IPR are not enforced, which occurs with probability $1-\lambda$, the MNF can still assemble a quantity $\delta^{H} x_{i}$, but now may face competition from the manufacturer, who can start to sell independently the quantity $\varphi_{V}^{M} x_{i}$. The size of $\varphi_{V}^{M}$ depends on the efficiency of imitation, which is related to the capacity to learn and reproduce the technology (i.e. on technological spillovers). In this case, the total quantity sold in the market is $\left(\delta^{H}+\varphi_{V}^{M}\right) x_{i}$, and the revenue of the final good supplier falls to $A\left(\delta^{H}+\varphi_{V}^{M}\right)^{(\alpha-1)} \delta^{H^{\alpha}} x_{i}^{\alpha}=\delta_{I} R$, where $\delta_{I} \equiv\left(\delta^{H}+\varphi_{V}^{M}\right)^{(\alpha-1)} \delta^{H^{\alpha}}<\delta$, and the subscript ${ }_{I}$ indicates imitation. Therefore, with probability $1-\lambda$, the MNF's revenue drops to $\delta_{I} R$, with $\delta_{I}<\delta$, because of the competition

\footnotetext{
${ }^{5}$ Notice that the subscript $M$ denotes the manufacturer, and the subscript $H$ the final good supplier.
} 
effect generated by the Southern manufacturer. Similarly, the revenue for the manufacturer is $A\left(\delta^{H}+\varphi_{V}^{M}\right)^{(\alpha-1)} \varphi_{V}^{M^{\alpha}} x_{i}^{\alpha}=\phi_{V} R$, where $\phi_{V}$ is the manufacturer's outside option under integration.

To summarize, in case of contractual breach, the expected revenue of the MNF is $\lambda \delta R+$ $(1-\lambda) \delta_{I} R$. Therefore, the MNF's share of the total revenue $R$ writes:

$$
\beta\left(1-\lambda \delta-(1-\lambda)\left(\delta_{I}+\phi_{V}\right)\right)+\lambda \delta+(1-\lambda) \delta_{I} \equiv \beta_{V}[\lambda]
$$

while manufacturer's share of the revenue writes:

$$
(1-\beta)\left(1-\lambda \delta-(1-\lambda)\left(\delta_{I}+\phi_{V}\right)\right)+(1-\lambda) \phi_{V} \equiv 1-\beta_{V}[\lambda]
$$

Notice that when $\lambda \rightarrow 1$ our model corresponds to Antràs and Helpman (2004), which represents our benchmark case with perfect IPR enforcement. When $\lambda$ decreases, the property rights on the physical assets are not sufficiently strong, and this shrinks the outside option of the MNF. This captures the idea that property rights on intangibles are crucial to determine the relative advantages of integration. Using (5) and (6), the profits of the MNF can be written as:

$$
\Pi_{V}^{H}=\beta_{V}[\lambda] R-z w_{N}
$$

where $\beta_{V}$ is the MNF's share of the revenue, $f_{V}$ is the fixed cost, and $w_{N}$ represents the wage rate in the North. Similarly, the operating profit of the integrated manufacturer writes:

$$
\Pi_{V}^{M}=\left(1-\beta_{V}[\lambda]\right) R-m w_{s}
$$

\subsection{Outsourcing}

We can now describe the incomplete contract problem in case of outsourcing. In the absence of an agreement at $t=2$, the final good supplier is left with a zero payoff. This is because, the MNF has no time to find an alternative supplier for the provision of the intermediate manufactured input. Similarly to the case of integration, the manufacturer can exploit the foreign technology only if intellectual property rights are not protected. In this case, the manufacturer can decide to free-ride on the technology and operate the technology on the side, to realize a positive revenue. Therefore, with probability $1-\lambda$, the Southern independent manufacturer imitates the variety, and realizes a share of the potential revenue equal to $A \varphi_{O}^{M^{\alpha}} x_{i}^{\alpha} R=\phi_{O} R$, where $\phi_{O}$ is its outside option under outsourcing.

Therefore, the MNF's share of revenue under outsourcing is as follows,

$$
\beta\left(1-(1-\lambda) \phi_{O}\right) \equiv \beta_{O}[\lambda] .
$$

Similarly, manufacturer's share of the revenue writes:

$$
(1-\beta)\left(1-(1-\lambda) \phi_{O}\right)+(1-\lambda) \phi_{O} \equiv 1-\beta_{O}[\lambda]
$$


Again, when $\lambda \rightarrow 1$ the model converges to the benchmark case in Antràs and Helpman (2004), where contractual breach under outsourcing leaves both parties with zero outside option. Differently in our set-up, when property rights are not perfectly enforced, the independent manufacturer can realize a positive outside option, by operating the technology on the side. Therefore, his outside option decreases with $\lambda$.

The operating profit of the MNF under outsourcing writes:

$$
\Pi_{O}^{H}=\beta_{O}[\lambda] R-z w_{N} .
$$

Similarly, the operating profit of the independent manufacturer writes:

$$
\Pi_{O}^{M}=\left(1-\beta_{O}[\lambda]\right) R-m w_{s}
$$

Following the literature, we assume that $\beta_{V}[\lambda]>\beta_{O}[\lambda]$. This captures the idea that the $\mathrm{MNF}$ is able to achieve a higher share of the surplus under vertical integration than under outsourcing.

\section{Equilibrium}

Under vertical integration, the final good producer and the manufacturer maximise (7) and (8) respectively, while under outsourcing they maximise (11) and (12). From the first order conditions of these programs and using (4) we can write the total operating profits as:

$$
\pi_{k}=A^{1 /(1-\alpha)} \theta^{\alpha /(1-\alpha)} \Psi_{k}\left(\beta_{k}[\lambda]\right)-w^{N} f_{k}, \quad k=\{V, O\}
$$

where

$$
\Psi_{k}\left(\beta_{k}[\lambda]\right)=\frac{1-\alpha\left(\beta_{k}[\lambda] \eta+\left(1-\beta_{k}[\lambda]\right)(1-\eta)\right)}{\left((1 / \alpha)\left(w_{n} / \beta_{k}[\lambda]\right)^{\eta}\left(w_{s} /\left(1-\beta_{k}[\lambda]\right)\right)^{1-\eta}\right)^{\alpha /(1-\alpha)}}, \quad k=\{V, O\} .
$$

It is important to note that $\Psi_{k}\left(\beta_{k}[\lambda]\right)$ is not necessarily increasing in $\lambda$. When $\lambda$ increases, the share of revenue retained by the final good producer, $\beta_{k}[\lambda]$, increases. However, due to incomplete contracts, this does not necessary increases profits. In fact, an increase in the share of MNF's revenues augments total profits only when the headquarter intensity, $\eta$, is sufficiently large. Conversely, for low levels of $\eta$, higher operating profits are associated with low revenue shares retained by the MNF. This results from standard hold-up theory: efficient allocation of property rights requires that ownership is allocated to the party that contributes more to the value of the relationship.

Since we have assumed that the fixed costs of vertical integration is higher than the one under outsourcing, $f_{V}>f_{O}$, and that vertical integration is associated with a higher share of revenues retained by the $\mathrm{MNF}, \beta_{V}[\lambda]>\beta_{O}[\lambda]$, then vertical integration can only arise when $\eta$ is high. Therefore, an improvement in IPR protection, $\lambda$, increases the difference in profitability between vertical integration and outsourcing if and only if: 


$$
\partial \beta_{V}[\lambda] / \partial \lambda>\partial \beta_{O}[\lambda] / \partial \lambda
$$

Under vertical integration the MNF has property rights on production facilities. This reinforces its ability to respond to contractual breaches and allows to reap a higher part of the surplus. Nonetheless, this ability shrinks if intellectual property rights are not well protected. In this case, even if the MNF controls the production facilities, it still faces competition from the independent manufacturer in case of contractual breach. This explains the importance of $\lambda$. Increasing the protection of IPR, $\lambda \uparrow$, generates a contraction in the manufacturer's outside option under both ownership structures. This reduction is inversely related to the manufacturer's ability to imitate the foreign technology. If its ability is higher in the case of vertical integration, stronger IPR are even more valuable for vertically integrated firms.

We now consider firm heterogeneity. We suppose that the productivity parameter $\theta$ is randomly drawn at the ex-ante stage $t_{O}$. The ranking chosen for fixed organizational costs, $f_{V}>f_{O}$, imply that less efficient firms choose outsourcing and more efficient firms select into vertical integration. The critical threshold above which firms outsource is given by the following zero profit condition:

$$
\pi^{O}=A^{\frac{1}{1-\alpha}} \theta^{\frac{\alpha}{1-\alpha}} \Psi_{O}\left(\beta_{O}[\lambda]\right)-f_{O} w_{n} \geq 0 .
$$

Using equation (16), we can then derive the minimum cutoff productivity for outsourcing to a South independent manufacturer, which is:

$$
\theta^{O}[\lambda]=\left(\frac{f_{O} w_{n}}{A \Psi_{O}\left(\beta_{O}[\lambda]\right)}\right)^{\frac{\alpha}{1-\alpha}} .
$$

Therefore, firms outsource in the South if their productivity level is higher than the threshold $\theta_{O}[\lambda]$

The vertical integration cutoff is obtained by setting the operating profits from vertical equal to those from outsourcing. In particular, the MNF chooses to be vertically integrated if and only if this strategy generates at least the same profits as the outsourcing strategy, namely, if $\pi^{V}-\pi^{O} \geq f_{V}>f_{O}$ :

$$
\pi^{V}-\pi^{O}=\left(A^{\frac{1}{1-\alpha}} \theta^{\frac{\alpha}{1-\alpha}} \Psi_{V}\left(\beta_{V}[\lambda]\right)-f_{V} w_{n}\right)-\left(A^{\frac{1}{1-\alpha}} \theta^{\frac{\alpha}{1-\alpha}} \Psi_{O}\left(\beta_{O}[\lambda]\right)-f_{O} w_{n}\right)>0 .
$$

Therefore, vertical integration is preferred to outsourcing for those firms having productivity at least equal to $\theta_{V}[\lambda]$ :

$$
\theta^{V}[\lambda]=\left(\frac{\left(f_{V}-f_{O}\right) w_{n}}{A\left(\Psi_{V}\left(\beta_{V}[\lambda]\right)-\Psi_{O}\left(\beta_{O}[\lambda]\right)\right)}\right)^{\frac{\alpha}{1-\alpha}} .
$$

In our framework, an increase in $\lambda$ move both productivity thresholds, (17) and (19), to the left. Less efficient firms begin to outsource, while the more efficient ones choose vertical integration. The threshold above which vertical integration is preferred to outsourcing also decreases. 
To compute the share of manufacturing inputs transacted within multinational firm boundaries, we assume foreign inputs are priced such that these input expenditures constitute the same multiple of operating profits under all organizational form. Integrating over firm's types and taking the ratio, gives the share of imports transacted within firm boundaries, which is:

$$
\sigma_{V}[\lambda]=\frac{\int_{\theta^{V}}^{\infty} A^{\frac{1}{1-\alpha}} \theta^{\frac{\alpha}{1-\alpha}} \Psi_{V}\left(\beta_{V}[\lambda]\right) d G(\theta)}{\int_{\theta_{O}}^{\theta^{V}} A^{\frac{1}{1-\alpha}} \theta^{\frac{\alpha}{1-\alpha}} \Psi_{O}\left(\beta_{O}[\lambda]\right) d G(\theta)+\int_{\theta^{V}}^{\infty} A^{\frac{1}{1-\alpha}} \theta^{\frac{\alpha}{1-\alpha}} \Psi_{V}\left(\beta_{V}[\lambda]\right) d G(\theta)} .
$$

Assuming that $\theta$ follows a Pareto distribution with parameter $\kappa>1 /(1-\alpha)-1$, and using thresholds (17) and (19) we obtain:

$$
\sigma_{V}[\lambda]=\frac{\frac{\Psi_{V}\left(\beta_{V}[\lambda]\right)}{\Psi_{O}\left(\beta_{O}[\lambda]\right)}}{\left[\left(\frac{\theta_{V}[\lambda]}{\theta_{O}[\lambda]}\right)^{\kappa-\left(\frac{1}{1-\alpha}-1\right)}-1\right]+\frac{\Psi_{V}\left(\beta_{V}[\lambda]\right)}{\Psi_{O}\left(\beta_{O}[\lambda]\right)}}
$$

where:

$$
\frac{\theta_{V}[\lambda]}{\theta_{O}[\lambda]}=\left[\frac{f_{O}}{f_{V}-f_{O}}\left(\frac{\Psi_{V}\left(\beta_{V}[\lambda]\right)}{\Psi_{O}\left(\beta_{O}[\lambda]\right)}-1\right)\right]^{-\frac{\alpha}{1-\alpha}} .
$$

Therefore, the relative share of intrafirm imports in equation (21), is increasing in the ratio $\Psi_{V}\left(\beta_{V}[\lambda]\right) / \Psi_{O}\left(\beta_{O}[\lambda]\right)$. This ratio is a complex function of $\lambda$. Nevertheless, we can establish that when $\phi_{O} / \phi_{V}$ is sufficiently small, then an increase in IPR protection, $\lambda$, will increase the share of intrafirm trade.

Proposition 1 Suppose that the intensity in headquarter services, $\eta$, is sufficiently large so that the function $\Psi_{k}\left(\beta_{k}[\lambda]\right)$ is increasing in $\beta_{k}[\lambda]$. Then, the ratio $\Psi_{V}\left(\beta_{V}[\lambda]\right) / \Psi_{O}\left(\beta_{O}[\lambda]\right)$ is increasing in $\lambda$ if and only if $\phi_{O} / \phi_{V}$ is sufficiently small.

Proof: Using standard derivation rules and developing computations, we have that $\partial\left(\Psi_{V}\left(\beta_{V}[\lambda]\right) / \Psi_{O}\left(\beta_{O}[\lambda]\right)\right) / \partial \lambda>0$ if and only if:

$$
\frac{\frac{\partial \Psi_{V}\left(\beta_{V}[\lambda]\right)}{\partial \beta_{V}[\lambda]}}{\frac{\partial \Psi_{O}\left(\beta_{O}[\lambda]\right)}{\partial \beta_{O}[\lambda]}} \frac{\Psi_{O}\left(\beta_{O}[\lambda]\right)}{\Psi_{V}\left(\beta_{V}[\lambda]\right)}>\frac{\phi_{O}}{\phi_{V}+\frac{\beta}{1-\beta}\left(\delta-\delta_{I}\right)} .
$$

Let's start with studying the following term:

$$
\frac{\frac{\partial \Psi_{k}\left(\beta_{k}[\lambda]\right)}{\partial \beta_{k}(\lambda]}}{\Psi_{k}\left(\beta_{k}[\lambda]\right)}=\frac{(1-\alpha) \eta+\alpha \eta^{2}+\beta_{k}[\lambda]^{2}(2 \eta-1)+2 \eta \beta_{k}[\lambda](1-(1-\eta))}{\left(1-\beta_{k}[\lambda]\right)(1-\alpha) \beta_{k}[\lambda]\left(1-\alpha(1-\eta)+\alpha \beta_{k}[\lambda](2 \eta-1)\right)}, \quad k \in\{V, O\},
$$

which is a decreasing function of $\beta_{k}[\lambda]$. Using this fact, and remembering that $\beta_{V}[\lambda]>\beta_{O}[\lambda]$, and that $\frac{\partial \Psi_{k}\left(\beta_{k}[\lambda]\right)}{\partial \beta_{k}[\lambda]}>0$, we can conclude that the left hand side of equation (23) is strictly positive, and smaller than one. Since the left hand side is strictly positive and the right hand side is increasing in the ratio $\phi_{O} / \phi_{V}$, than a sufficient condition for the inequality in (23) to hold is that $\phi_{O} / \phi_{V}$ is sufficiently small. Q.E.D. 
The condition in (23) is likely to be satisfied for many reasonable values of the parameters. For instance, let's consider a simplified case in which we set $\delta_{I}=\delta-\phi_{V}$. Then, in case of imitation, the manufacturer diverts revenue $\phi_{V} R$ from the final good producer, while the latter keeps the residual revenue $\left(\delta-\phi_{V}\right) R$. Notice that we keep constant total sector revenues, i.e. $\delta R$. Additionally, let's rewrite (23) using $\beta=\delta=1 / 2, \lambda \rightarrow 1$, and $\eta \rightarrow 1$. Then, the share of intrafirm trade increases with $\lambda$ if and only if $\frac{\phi_{O}}{\phi_{V}}<1$. This means that a vertically integrated manufacturer is relatively more able to replicate the variety produced by the final good producer. The condition $\lambda \rightarrow 1$ is the more stringent, because a reduction in $\lambda$ increases the left hand side of (23), so that for lower levels of IPR protection the inequality will be further relaxed.

The result in Proposition 1 states that an increase in IPR protection increases the relative profitability of vertical integration whenever the outside option of the manufacturer under outsourcing, $\phi_{O}$, is smaller than its outside option under integration, $\phi_{V}$. Indeed, the term $\phi_{k}$ captures the manufacturer's ability to free-ride on the technology invented by the Northern multinational in case of contractual breach. Therefore, two scenarios are possible. If vertical integration allows to grab sufficiently higher knowledge through technological spillover, than an increase in IPR enforcement is more valuable for vertical integrated firms. On the other hand, if technology spillovers are higher under outsourcing, than the opposite result holds. Both results are theoretically possible. However, in line with the empirical evidence described in Section 1, we claim that knowledge spillovers are larger under vertical integration.

\section{Empirical evidence}

The goal of this section is to quantify empirically the role of IPR in affecting the global sourcing decisions of firms. Since our model describes firm organizational decisions, firm-level data would seem more appropriate. One possibility would be to use the French firm-level data providing information on the global sourcing practice of firms, called EIIG (Echanges Internationaux Intra-Groupe), but this data have several limitations. Firstly, it is a survey available only for 1999, and so it misses a time dimension which is crucial to evaluate the effect of IPR. Secondly, it covers only French firms that traded more than 1 million euros in 1999, which are owned by manufacturing groups that control at least fifty percent of the equity capital of an affiliate based outside France.

Our approach will then exploit industry-level variations, taking advantage from U.S. Related-Party Trade database made available by Pol Antràs. ${ }^{6}$ The dataset provide information on goods transactions across borders within and outside of firm boundaries over the period 2000-2010. This database defines a related party as a foreign counterpart in which the U.S. importer has at least $6 \%$ equity. This is lower than the conventional $10 \%$ threshold used by the IMF to identify FDI. However, Nunn and Trefler (2008) provide suggestive evidence that related party trade is generally associated with one of the entities having a controlling

\footnotetext{
${ }^{6}$ See Chapters 5 and 8 in Antràs (2015), and Antràs' web page http://scholar.harvard.edu/antras/books.
} 
stake in the other entity. In the following sections we present the description of the data, our empirical strategy, and a discussion of the results.

\subsection{Data Description}

To capture U.S. firms' decision to integrate foreign suppliers, we follow the recent literature using the share of related party imports in total U.S. imports, i.e. (Related Trade)/(Related Trade + Non-Related Trade). This is known in the literature as share of intra-firm imports, and varies at the exporting country-industry-year level over the period 2000-2010. In line with our theoretical set-up, we follow Antràs and Chor (2013) who mapped NAICS industry codes to six-digit IO2002 industries using a correspondence from the Bureau of Economic Analysis (BEA). This mapping provides the advantage to construct measures of headquarter intensity of the U.S. industry buying those inputs. This is different from using the raw data in NAICS codes, which instead give information on the industry of the product being imported. Additionally, using the Wright (2014) methodology, the IO2002 classification can isolate the intermediate input component of import flows. ${ }^{7}$ This cleaning should eliminate possible confounding effects for the role of IPR due to the fact that original U.S. product level data combine intermediate input as well as finished goods imports. Data used are for 193 countries and 253 manufacturing industries. One shortcoming of using U.S. manufacturing data is related to the fact that, in recent years, different multinationals have concentrated in pre-production activities such as design and engineering. The presence of "factoryless goods producers", as referred to in Bernard and Fort (2015), introduces errors sice the IO tables are not able to capture outsourcing by wholesalers. ${ }^{8}$ Nonetheless, this dataset remains one of the most reliable sources of information concerning global value chains.

To better capture the type of global sourcing in our model, it is important to distinguish between trade within U.S. multinationals and trade within foreign multinational operating in the U.S. We therefore follow Antras and apply the Nunn and Trefler (2013) correction. This implies dropping from the initial set of countries those for which shipments from foreign headquarters to their U.S. affiliates are likely to be predominant, relative to shipments to U.S. parents from their foreign affiliates in those countries. Specifically, this consists in keeping those countries for which the share of U.S. headquarters is above 50 percent. ${ }^{9}$ However, this sample restriction has almost no impact on our estimates.

Our model highlights a new mechanism explaining the propensity to transact a particular input within firm boundaries. Specifically, we show that stronger IPR might encourage relatively more vertical integration. To measure IPR protection we use Park (2008) who updates the index of patent protection published in Ginarte and Park (1997). The new index, always calculated in periods of 5 years, has now been updated to 2005 and extended to 122 countries. The IPR index ranges between 0 and 5 , with 5 being the highest level of IPR protection.

\footnotetext{
${ }^{7}$ For more details on the Wright (2014) methodology see appendix B.3 in Antràs (2015).

${ }^{8}$ For instance, starting from 2004, Apple has become a wholesale firm while production of its product has been carried by other firms, such as Foxconn in China.

${ }^{9}$ The dropped destination countries are Iceland, Italy, Finland, Liechtenstein, and Switzerland.
} 
After merging the IPR index with data on shares of intra-firm imports we are left with two years: 2000 and 2005.

To control for headquarter intensity of an industry, we follow the bulk of the literature and proxy for it with measures of physical capital, skill and R\&D intensities of U.S. manufacturing firms (see Nunn and Trefler (2013) and Antràs and Chor (2013) among others). Capital intensity is separated into expenditures on capital equipment (computers and data processing), and on capital structure (automobile and trucks). Skill intensity is the ratio of the number of non-production workers divided by total employment. R\&D intensity is computed as $R \& D$ expenditures divided by sales. The underlying data from NBER-CES and Orbis are available on a yearly basis, but others, like specificity and contractability, are not. ${ }^{10}$ Therefore, to capture the average buyer in an industry, Antràs and Chor (2013) and Antràs (2015) use weighted average measures of headquarter intensity. In our benchmark estimation, where we use the Wright (2014) methodology to control for the intermediate input component in trade flows, we rely on those averaged industry measures. Then, as a robustness check we run a similar regression combining time varying industry variables at the NAICS level and BEC classification to identify intermediates, and results do not change.

To control for country level characteristics we use different measures. From the World Development Indicators (World Bank), we use a time varying governance indicator that captures perceptions of the extent to which agents have confidence in and abide by the rules of society (rule of law). We also add a dummy variable that equals one when the importing country is a WTO member. Finally, since our theoretical framework is characterized by incomplete contracts, we include a contractibility measure at the IO2002 industrial level. This variable, borrowed from Antràs and Chor (2013) who build on the methodology of Nunn (2007), measures the importance of relationship-specific investments across industries. It is normalized so that higher levels imply lower dependence on formal contract enforcement, and averaged over time.

\subsection{Empirical Specification}

In this section we describe our empirical specification for disentangling the effect of IPR on the propensity of transacting a particular input within firm boundaries. We use the U.S. data on intra-firm imports to test part of the prediction implied by Proposition 1, namely, that intra-firm share is increasing in the level of IPR.

Following our model, and to address possible biases coming from the endogenous location decisions of firms regarding stages of production, we exploit the country-industry variation in our intra-firm shares. Our baseline regression is then:

$$
S_{i c t}=\beta_{1}+\beta_{2} I P R_{c t}+\beta_{3} \bar{X}_{i}+\beta_{4} I P R_{c t} * \bar{c}_{i}+\beta_{5} Z_{c t}+\mu_{c}+\gamma_{t}+\epsilon_{i c t},
$$

where $S_{i c t}$ is intra-firm import shares in industry $i$, importing from country $c$, in a given

\footnotetext{
${ }^{10}$ For additional information on the different database used see Appendices in Antràs and Chor (2013) and B.6 in Antràs (2015).
} 
year $t$. IPR $R_{c t}$ is the IPR index at the country-year level. The vector $\bar{X}_{i}$ comprises a set of U.S. industry controls for headquarter intensity averaged over time and the average buyer contractibility measure $\bar{c}_{i}$. The interaction term between average buyer contractibility and IPR, IPR $R_{c t} * \bar{c}_{i}$, captures the impact of stronger intellectual property rights on intra-firm import shares for those industries with relatively low relation specific investments. $Z_{c t}$ are destination country controls like rule of law and WTO membership. We also control for destination country unobservable characteristics and for any trend using country and year fixed effects, $\mu_{c}$ and $\gamma_{t}$ respectively. Finally, we cluster the standard errors by country and time, since our key explanatory variable related to the level of IPR protection in a country, varies by country and time.

Our theory predicts that if vertical integration allows to obtain sufficiently high knowledge through technological spillover, than an increase in IPR protection is more valuable for vertical integrated firms. Thus, IPR should encourage relatively more intra-firm import, and we expect our coefficient of interest, $\beta_{2}$, to be positive. The industry-level controls in the vector $\bar{X}_{i}$ identify the average characteristics of the buying U.S. industry. Rule of law and WTO dummy capture time varying destination country characteristics. The average buyer contractibility coefficient, $\beta_{3}$, is expected to be negative indicating that industries with a lower dependence on formal contract enforcement should be less inclined to import the input within firm boundaries. The interaction between IPR and average buyer contractibility captures the effect of better contract enforcement for those industries with relatively low relation specific investments. We expect the coefficient of this interaction, $\beta_{4}$, to be negative, so that the effect of IPR on imports is larger for intermediate inputs that are relationship-specific.

\section{Empirical Results}

\subsection{Benchmark Specification}

We now turn to our estimations. OLS estimates of equation (25), are reported in Table 1. The first column estimates equation (25) with only IPR variable and fixed effects. The estimated coefficient for IPR is positive and statistically significant, which supports the idea that an increase in IPR protection is more valuable for vertical integrated firms. This is coherent with our intuition that vertical integration allows to obtain sufficiently high knowledge through technological spillovers. Results do not change when adding the WTO dummy in column (2).

In column (3) we control for average headquarter intensity characteristics. In column (4) we add the contractibility measure of the buyer, which is negative and statistically significant, supporting the hypothesis that industries with a lower dependence on formal contract enforcement, should be less inclined to import the input within firm boundaries. Column (5) controls for rule of law, which is conventionally used as a measure of the quality of contract enforcement at the country level. The impact of this variable is significant and negative. This is natural because an increase in the quality of contract enforcement should facilitate writing contract with independent parties. Finally in column (6) we control for the interaction between IPR 
and average buyer contractibility, which is negative but not statistically significant.

Table 1: IPR and Intermediate Intrafirm Trade Shares

\begin{tabular}{|c|c|c|c|c|c|c|}
\hline Dep. Var. $\frac{\text { Intrafirm Imp }}{\text { Total Imports }}$ & (1) & $(2)$ & $(3)$ & $(4)$ & $(5)$ & (6) \\
\hline$\overline{\mathrm{IPR}}$ & $\begin{array}{c}0.032^{* * *} \\
(0.006)\end{array}$ & $\begin{array}{c}0.034^{* * *} \\
(0.006)\end{array}$ & $\begin{array}{c}0.034^{* * *} \\
(0.006)\end{array}$ & $\begin{array}{c}0.034^{* * *} \\
(0.006)\end{array}$ & $\begin{array}{c}0.034^{* * *} \\
(0.007)\end{array}$ & $\begin{array}{c}0.026^{* * *} \\
(0.010)\end{array}$ \\
\hline WTO member & & $\begin{array}{l}-0.008 \\
(0.014)\end{array}$ & $\begin{array}{l}-0.008 \\
(0.014)\end{array}$ & $\begin{array}{l}-0.007 \\
(0.014)\end{array}$ & $\begin{array}{l}-0.004 \\
(0.015)\end{array}$ & $\begin{array}{c}-0.004 \\
(0.015)\end{array}$ \\
\hline $\log \mathrm{R} \& \mathrm{D} /$ Sales & & & $\begin{array}{c}0.024^{* * *} \\
(0.003)\end{array}$ & $\begin{array}{c}0.020 * * * \\
(0.003)\end{array}$ & $\begin{array}{c}0.020^{* * *} \\
(0.003)\end{array}$ & $\begin{array}{c}0.021^{* * *} \\
(0.003)\end{array}$ \\
\hline $\log$ (Skill/Unskilled) & & & $\begin{array}{c}0.034^{* * *} \\
(0.010)\end{array}$ & $\begin{array}{c}0.027^{* * * *} \\
(0.010)\end{array}$ & $\begin{array}{c}0.027^{* * *} \\
(0.010)\end{array}$ & $\begin{array}{c}0.027^{* * *} \\
(0.010)\end{array}$ \\
\hline log (Capital Struct/Labor) & & & $\begin{array}{c}-0.016^{*} \\
(0.009)\end{array}$ & $\begin{array}{c}-0.014 \\
(0.009)\end{array}$ & $\begin{array}{c}-0.014 \\
(0.009)\end{array}$ & $\begin{array}{l}-0.013 \\
(0.009)\end{array}$ \\
\hline log (Capital Equip/Labor) & & & $\begin{array}{c}0.048^{* * *} \\
(0.008)\end{array}$ & $\begin{array}{c}0.054^{* * *} \\
(0.008)\end{array}$ & $\begin{array}{c}0.054^{* * *} \\
(0.008)\end{array}$ & $\begin{array}{c}0.054^{* * *} \\
(0.008)\end{array}$ \\
\hline Contractibility & & & & $\begin{array}{c}-0.070^{* * *} \\
(0.014)\end{array}$ & $\begin{array}{c}-0.070^{* * *} \\
(0.014)\end{array}$ & $\begin{array}{r}-0.131^{* *} \\
(0.059)\end{array}$ \\
\hline Rule of law & & & & & $\begin{array}{c}-0.038^{* * *} \\
(0.011)\end{array}$ & $\begin{array}{c}-0.038 * * * \\
(0.011)\end{array}$ \\
\hline Contractibility*IPR & & & & & & $\begin{array}{c}0.016 \\
(0.016)\end{array}$ \\
\hline
\end{tabular}

\begin{tabular}{lcccccc}
\hline Observations & 19,536 & 19,536 & 19,536 & 19,536 & 19,536 & 19,536 \\
R-squared & 0.156 & 0.156 & 0.179 & 0.180 & 0.181 & 0.181 \\
Country FE & Yes & Yes & Yes & Yes & Yes & Yes \\
Year FE & Yes & Yes & Yes & Yes & Yes & Yes \\
\hline \hline
\end{tabular}

Notes: The regressions are OLS estimations of equation (25). The dependent variable is the U.S. intrafirm import share of U.S. importing industry $i$ in year $t$. Only manufacturing sectors. Wright (2014) correction for intermediates. Nunn and Trefler (2013) destination countries correction. Heteroskedasticity-robust standard errors clustered by country-year are reported in parentheses. $* * *, * *$, and $*$ indicate significance at the 1,5 and 10 percent levels respectively. 


\subsection{Robustness and Sensitivity Analysis}

In this section we run some robustness checks to overcome possible limitations of the analysis. Firstly, we run a similar regression as in equation (25), but this time we keep time varying industry variables. Therefore, we switch to NAICS industry level classification, and then combine it with BEC classification to restrict the analysis to intermediates only. The data are always from U.S. Related-Party Trade database, which is available for 390 manufacturing industries. The limitation of this approach is that the NAICS data are reported based on the sector of the good being transacted, and do not contain information on the sector that is purchasing the good. Our regression becomes:

$$
S_{i c t}=\beta_{1}+\beta_{2} I P R_{c t}+\beta_{3} X_{i t}+\beta_{4} Z_{c t}+\mu_{c}+\gamma_{t}+\epsilon_{i c t}
$$

where $S_{i c t}$ is the share of intra-firm trade, defined as the ratio of related-party imports to the sum of related and non-related imports. Notice that with NAICS classification, we cannot control for buyer characteristics, such as buyer contractibility.

OLS estimates of equation (26), are reported in Table 2. Our finding on the effect of IPR on the propensity of transacting a particular input within firm boundaries turns out to be robust also when using NAICS classification. The coefficient of IPR is positive and significant, and its magnitude similar to that in Table 1.

Table 2: IPR and Intrafirm Trade Shares (NAICS Intermediates)

\begin{tabular}{|c|c|c|c|c|}
\hline Dep. Var. $\frac{\text { Intrafirm Imp }}{\text { Total Imports }}$ & (1) & $(2)$ & $(3)$ & (4) \\
\hline $\mathrm{IPR}$ & $\begin{array}{c}0.025^{* * *} \\
(0.006)\end{array}$ & $\begin{array}{c}0.026^{* * *} \\
(0.006)\end{array}$ & $\begin{array}{c}0.029^{* * *} \\
(0.007)\end{array}$ & $\begin{array}{c}0.027^{* * *} \\
(0.007)\end{array}$ \\
\hline Rule of Law & & $\begin{array}{c}-0.027^{* * *} \\
(0.010)\end{array}$ & $\begin{array}{c}-0.026^{* * *} \\
(0.010)\end{array}$ & $\begin{array}{c}-0.026^{* * *} \\
(0.010)\end{array}$ \\
\hline WTO member & & & $\begin{array}{l}-0.014 \\
(0.014)\end{array}$ & $\begin{array}{l}-0.011 \\
(0.013)\end{array}$ \\
\hline $\log R \& D /$ Sales & & & & $\begin{array}{c}0.030 * * * \\
(0.002)\end{array}$ \\
\hline $\log$ (Skill/Unskilled) & & & & $\begin{array}{c}0.027^{* * *} \\
(0.007)\end{array}$ \\
\hline log (Capital Struct/Labor) & & & & $\begin{array}{c}-0.048^{* * *} \\
(0.007)\end{array}$ \\
\hline log (Capital Equip/Labor) & & & & $\begin{array}{c}0.058^{* * *} \\
(0.006)\end{array}$ \\
\hline Observations & 28,027 & 28,027 & 28,027 & 28,027 \\
\hline R-squared & 0.137 & 0.137 & 0.137 & 0.164 \\
\hline Country FE & Yes & Yes & Yes & Yes \\
\hline Year FE & Yes & Yes & Yes & Yes \\
\hline
\end{tabular}

Notes: The regressions are OLS estimations of equation (25). The dependent variable is the U.S. intrafirm import share in NAICS industry $i$ in year $t$. Only manufacturing sectors. Heteroskedasticity-robust standard errors clustered by country-year are reported in parentheses. $* * *, * *$, and $*$ indicate significance at the 1,5 and 10 percent levels respectively. 
Then, we explore the role of differences in industry-level sensitivity to IPR, to see whether the impact of IPR enforcement is enhanced in patent-sensitive industries. To distinguish the industry classification into patent-sensitive and insensitive industries, we follow Table 1 in Cohen et al. (2000) and generate a dummy variable that takes the value 1 if the industry ranking of effectiveness of patent protection is higher than 38 percent. Our measure is similar to the one used in Ivus (2010). This variable enables us to consider the additional effect of IPR on patent-sensitive industries. We expect a stronger effect of IPR on the intra-firm import share of those patent-sensitive industries.

Table 3 reports the results controlling for industry-level sensitivity. In line with Ivus (2010), we find a stronger effect of IPR on share of intra-firm of patent-sensitive industries.

Table 3: IPR and Patent Sensitivity

\begin{tabular}{|c|c|c|c|c|c|c|}
\hline Dep. Var. $\frac{\text { Intrafirm Imp }}{\text { Total Imports }}$ & (1) & $(2)$ & (3) & (4) & $(5)$ & $(6)$ \\
\hline$\overline{\mathrm{IPR}}$ & $\begin{array}{c}0.035^{* * *} \\
(0.007)\end{array}$ & $\begin{array}{c}0.033^{* * *} \\
(0.009)\end{array}$ & $\begin{array}{c}0.034^{* * *} \\
(0.009)\end{array}$ & $\begin{array}{c}0.034^{* * *} \\
(0.009)\end{array}$ & $\begin{array}{c}0.034^{* * *} \\
(0.009)\end{array}$ & $\begin{array}{c}0.039^{*} * * \\
(0.013)\end{array}$ \\
\hline $\mathrm{IPR}^{*} \mathrm{PAT}$ & $\begin{array}{c}0.016^{* * *} \\
(0.003)\end{array}$ & $\begin{array}{c}0.016^{* * *} \\
(0.003)\end{array}$ & $\begin{array}{c}0.009^{* * *} * \\
(0.003)\end{array}$ & $\begin{array}{c}0.010^{* * *} \\
(0.003)\end{array}$ & $\begin{array}{c}0.010^{* * *} \\
(0.003)\end{array}$ & $\begin{array}{c}0.010^{* * *} \\
(0.003)\end{array}$ \\
\hline WTO member & & $\begin{array}{c}0.010 \\
(0.016)\end{array}$ & $\begin{array}{c}0.008 \\
(0.017)\end{array}$ & $\begin{array}{c}0.008 \\
(0.017)\end{array}$ & $\begin{array}{c}0.016 \\
(0.017)\end{array}$ & $\begin{array}{c}0.016 \\
(0.017)\end{array}$ \\
\hline $\log \mathrm{R} \& \mathrm{D} /$ Sales & & & $\begin{array}{c}0.023^{* * *} \\
(0.003)\end{array}$ & $\begin{array}{c}0.021^{* * *} \\
(0.003)\end{array}$ & $\begin{array}{c}0.021^{* * *} \\
(0.003)\end{array}$ & $\begin{array}{c}0.021^{* * *} \\
(0.003)\end{array}$ \\
\hline $\log$ (Skill/Unskilled) & & & $\begin{array}{l}0.022^{*} \\
(0.011)\end{array}$ & $\begin{array}{c}0.017 \\
(0.011)\end{array}$ & $\begin{array}{c}0.017 \\
(0.011)\end{array}$ & $\begin{array}{c}0.017 \\
(0.011)\end{array}$ \\
\hline log (Capital Struct/Labor) & & & $\begin{array}{c}-0.034^{* * *} \\
(0.012)\end{array}$ & $\begin{array}{c}-0.029^{* *} \\
(0.012)\end{array}$ & $\begin{array}{c}-0.029^{* *} \\
(0.012)\end{array}$ & $\begin{array}{c}-0.030^{* *} \\
(0.012)\end{array}$ \\
\hline $\log$ (Capital Equip/Labor) & & & $\begin{array}{c}0.054^{* * *} \\
(0.011)\end{array}$ & $\begin{array}{c}0.059^{* * *} * \\
(0.011)\end{array}$ & $\begin{array}{c}0.059^{* * *} * \\
(0.011)\end{array}$ & $\begin{array}{c}0.059 * * * \\
(0.011)\end{array}$ \\
\hline Contractibility & & & & $\begin{array}{c}-0.082^{* * *} \\
(0.017)\end{array}$ & $\begin{array}{c}-0.082^{* * *} \\
(0.017)\end{array}$ & $\begin{array}{l}-0.032 \\
(0.091)\end{array}$ \\
\hline Rule of law & & & & & $\begin{array}{c}-0.073^{* * *} * \\
(0.017)\end{array}$ & $\begin{array}{c}-0.073^{* * *} \\
(0.017)\end{array}$ \\
\hline Contractibility*IPR & & & & & & $\begin{array}{l}-0.013 \\
(0.024)\end{array}$ \\
\hline Observations & 10,938 & 10,938 & 10,938 & 10,938 & 10,938 & 10,938 \\
\hline R-squared & 0.163 & 0.163 & 0.180 & 0.182 & 0.183 & 0.183 \\
\hline Country FE & Yes & Yes & Yes & Yes & Yes & Yes \\
\hline Year FE & Yes & Yes & Yes & Yes & Yes & Yes \\
\hline
\end{tabular}

Notes: The regressions are OLS estimations of equation (25). The dependent variable is the U.S. intra-firm import share in NAICS industry $i$ in year $t$. Only manufacturing sectors. Heteroskedasticity-robust standard errors clustered by country-year are reported in parentheses. $* * *, * *$, and $*$ indicate significance at the 1,5 and 10 percent levels respectively. 
Finally, we should be cautious in interpreting the OLS estimates, because the choice of IPR made by developing countries could be endogenous. The main reason is that the size of FDI and outsourcing attracted by a country, could also influence the propensity to protect IPR, raising a possible reverse-causality issue. For instance, developed countries could exert pressure on countries hosting FDI to modify their institutions, causing an upward bias of OLS estimates. In addition, FDI, outsourcing and IPR could all be influenced by omitted confounding variables. Certain characteristics, such as market size, technological development, for which it is difficult to control for empirically, could contribute in attracting high levels of FDI. These omitted characteristics might be related to IPR. For example, developing countries can reduce their propensity to enforce IPR to exploit the benefits of imitation. This would instead cause a downwards bias in OLS estimates. ${ }^{11}$

To account for these problems, we estimate equation (25) using instrumental variable (IV) techniques. Our IV strategy uses two instruments for IPR. First, similarly to Ivus (2010) and Ivus et al. (2016), we use a dummy equal to one for former British and French colonies. The use of colonial origin is justified by the fact that several former colonies of England and France strengthened their IPR protection earlier than countries that did not have a colonial past. Therefore, the IPR reforms undertaken by the latter during 1990-2005 could be legitimately interpreted as an exogenous imposition of TRIPS. Since non-colony is a dummy variable with no time variation, our specification cannot include country fixed effects.

As a second instrument, we use outwards migrations of students. A similar instrument, based on student migration has been recently proposed in Auriol et al. (2015). The idea is that the presence of student migrating from the home country to foreign destinations, can influence the attitude towards intellectual property rights and technological progress in the home country. The empirical literature supports the idea that migrant students have an impact on institutional reforms. Spilimbergo (2009) shows that individuals educated in foreign democratic countries can promote democracy in their home country. Similarly, migrant students could have an impact on the attitude towards different institutions, such as IPR. Nevertheless, students migration can also determine a brain-drain, which could be detrimental to technological progress. In this respect, the empirical literature highlights a positive effect of student migrations on technological transfers. For instance Dominguez Dos Santos and Postel-Vinay (2003) and Dustmann et al. (2003), put the accent on the positive effects of return migration on technological transfers. Also, Naghavi and Strozzi (2015) have shown that the knowledge acquired by emigrants abroad can flow back into the innovation sector at home. Our additional instrument is then the number of student migrating to democratic countries, as defined by the Freedom House indicators. ${ }^{12}$ The variable is lagged five years.

The IV estimates are reported in Tables 4. The first column reports IV estimates using non-colonial status. According to the first stage estimates, non-colony have the higher level of IPR. From the second stage estimates, we find that the IV coefficient is positive and

\footnotetext{
${ }^{11}$ Notice that rule of law could also suffer from endogeneity concerns (see Nunn (2007)). Therefore, we omit this variable from the following analysis.

${ }^{12}$ Data are taken from Spilimbergo (2009).
} 
statistically significant, which support the idea that strong IPR reinforce intra-firm trade. In column (2) we show results from adding a second instrument, which also allows to test for the over-identification restrictions. The size of outward migration of students also has a positive on IPR protection. Finally in column (3) we present the benchmark OLS estimation after excluding rule of law and country fixed effect. Both IV estimations confirm the benchmark case in column (3). Comparing columns (1) and (2) to column (3) we can conclude that the bias related to endogeneity appears to be small.

Table 4: Instrumenting IPR

\begin{tabular}{|c|c|c|c|}
\hline Dep. Var. $\frac{\text { Intrafirm Imp }}{\text { Total Imports }}$ & $\begin{array}{l}\text { (1) } \\
\text { IV }\end{array}$ & $\begin{array}{l}(2) \\
\text { IV }\end{array}$ & $\begin{array}{c}(3) \\
\text { OLS }\end{array}$ \\
\hline IPR & $\begin{array}{c}0.076^{* * *} \\
(0.016)\end{array}$ & $\begin{array}{c}0.084^{* * *} \\
(0.015)\end{array}$ & $\begin{array}{c}0.085^{* * *} \\
(0.010)\end{array}$ \\
\hline WTO member & $\begin{array}{c}0.063^{* * *} \\
(0.018)\end{array}$ & $\begin{array}{c}0.050^{* * *} \\
(0.023)\end{array}$ & $\begin{array}{c}0.058^{* * *} \\
(0.018)\end{array}$ \\
\hline $\log \mathrm{R} \& \mathrm{D} /$ Sales & $\begin{array}{c}0.020^{* * * *} \\
(0.003)\end{array}$ & $\begin{array}{c}0.021^{* * *} \\
(0.002)\end{array}$ & $\begin{array}{c}0.020^{* * *} \\
(0.002)\end{array}$ \\
\hline $\log$ (Skill/Unskilled) & $\begin{array}{c}0.026^{* * *} \\
(0.010)\end{array}$ & $\begin{array}{c}0.026^{* * *} \\
(0.010)\end{array}$ & $\begin{array}{c}0.027^{* * *} \\
(0.010)\end{array}$ \\
\hline log (Capital Struct/Labor) & $\begin{array}{l}-0.013 \\
(0.010)\end{array}$ & $\begin{array}{l}-0.015 \\
(0.013)\end{array}$ & $\begin{array}{l}-0.013 \\
(0.010)\end{array}$ \\
\hline log (Capital Equip/Labor) & $\begin{array}{c}0.054^{* * *} \\
(0.008)\end{array}$ & $\begin{array}{c}0.054^{* * *} \\
(0.008)\end{array}$ & $\begin{array}{c}0.054^{* * *} \\
(0.008)\end{array}$ \\
\hline Contractibility & $\begin{array}{c}-0.074^{* * *} \\
(0.014)\end{array}$ & $\begin{array}{c}-0.074^{* * *} \\
(0.014)\end{array}$ & $\begin{array}{c}-0.074^{* * *} \\
(0.014)\end{array}$ \\
\hline $\begin{array}{l}\text { Country FE } \\
\text { Year FE }\end{array}$ & $\begin{array}{l}\text { No } \\
\text { Yes }\end{array}$ & $\begin{array}{l}\text { No } \\
\text { Yes }\end{array}$ & $\begin{array}{l}\text { No } \\
\text { Yes }\end{array}$ \\
\hline IV no colony: & $\begin{array}{c}1.076^{* * *} \\
(0.108)\end{array}$ & $\begin{array}{c}1.110^{* * *} \\
(0.000)\end{array}$ & \\
\hline IV migrants: & & $\begin{array}{c}0.14^{* * *} \\
(1.001)\end{array}$ & \\
\hline Observations & 19,536 & 19,536 & 19,536 \\
\hline R-squared & 0.071 & 0.071 & 0.071 \\
\hline F-stat first stage & 98.33 & 47.41 & \\
\hline Sargan Test (p-val) & & 0.73 & \\
\hline
\end{tabular}

Notes: The regressions are OLS estimations of equation (25). The dependent variable is the U.S. intrafirm import share in NAICS industry $i$ in year $t$. Only manufacturing sectors. Heteroskedasticity-robust standard errors clustered by country-year are reported in parentheses. $* * *, * *$, and $*$ indicate significance at the 1,5 and 10 percent levels respectively. 


\section{Conclusion}

Intellectual property rights can have non-trivial effects on ownership structures of multinational firm. In this paper, we explore, theoretically and empirically, the interaction of IPR with physical property rights to determine the relative attractiveness of vertical integration with respect to outsourcing. Our model embeds the property right approach in a global value chains context. Departing from the existent literature on global sourcing, we assume that production in the South exposes multinational firms to a risk of imitation from the manufacturer.

Our model shows that stronger IPR increase the profitability of multinationals under both ownership structures. Additionally, we find that, under reasonable assumptions, higher levels of IPR affect relatively more vertical integration than outsourcing. This result derives from the fact that we model vertical integration as inducing more knowledge spillover than outsourcing. This makes a vertically integrated firm more exposed to the threat of imitation when IPR are weak. Therefore, stronger IPR encourage by a larger extent the imports of intermediates through vertical integration.

Our results are tested using US intra-firm trade from the U.S. Census Bureau's Related Party Trade Database. According to the estimates, an increase in IPR enforcement is more valuable for vertical integrated firms. We also assess the sensitivity and robustness of our results to alternative specifications, such as changing industry classification and introducing differences in the industry-level sensitivity to IPR. Finally, to correct for the potential endogeneity of the strength of IPR protection, we propose a two-stage instrumental variable approach, based on differences in the colonial status of countries and on student migrations. All specifications confirm the main finding that an increase in IPR protection increases the relative share of intra-firm imports. 


\section{References}

Antràs, P., 2014. Firms, Contracts, and Trade Structure. Quarterly Journal of Economics, $118(4), 1375-1418$.

Antràs, P., 2014. Grossman-Hart (1986) Goes Global: Incomplete Contracts, Property Rights, and the International Organization of Production. Journal of Law, Economics and Organization, 30(1), 118-175.

Antràs, P., 2015. Global Production: Firms, Contracts, and Trade Structure. Princeton University Press, 336 pp.

Antràs, P., Chor, D., 2013. Organizing the Global Value Chain. Econometrica, 81(6), 21272204

Antràs, P., Helpman, E., 2004. Global Sourcing. Journal of Political Economy, 112(3), 552580 .

Antràs, P., Yeaple, S., 2014. Multinational Firms and the Structure of International Trade. Handbook of International Economics, 4, 1414-44.

Auriol, E.,S. Biancini, R. Paillacar, 2015. Intellectual property rights protection and Trade. CEPR Discussion Paper.

Bernard, A., Fort, T., 2004. Factoryless Goods Producing Firms. American Economic Review Papers and Proceedings, 105(5), 518-23.

Bertrand, M., Duflo, E., Mullainathan, S., 2004. How Much Should We Trust Differences-inDifferences Estimates?. The Quarterly Journal of Economics, 119(1), 249-275.

Blomström, M., Sjöholm, F., 1999. Technology transfer and spillovers: does local participation with multinationals matter?. European economic review, 43(4), 915-923.

Branstetter, Lee, 2006. Is foreign direct investment a channel of knowledge spillovers? Evidence from Japan's FDI in the United States. Journal of International economics, 68(2), $325-344$.

Branstetter, L., Saggi, K., 2011. Intellectual property rights, foreign direct investment and industrial development. The Economic Journal, 121(55), 1161-1191.

Cohen, W.M., Nelson, R.R., Walsh, J.P., 2000. Protecting their Intellectual Assets: Appropriability Conditions and Why U.S. Manufacturing Firms Patent (or Not). NBER Working Paper no.7552,

Dominguez Dos Santos, M.,F. Postel-Vinay, 2003. Migration as a source of growth: the perspective of a developing country. Journal of Population Economics, 16(1), 161-175. 
Dustmann, C.,I. Fadlon, Y. Weiss 2003. Return Migration, Human Capital Accumulation and the Brain Drain. Journal of Development Economics, 95(1), 58-67.

Fink, C., Maskus, K. E., 2005. Intellectual property and development: lessons from recent economic research. World Bank.

Ginarte, J. C., and Park, W. G., 1997. Determinants of patent rights: A cross-national study. Research policy, 26(3), 283-301.

Görg, H., and Strobl, E., 2005. Spillovers from foreign firms through worker mobility: An empirical investigation.. The Scandinavian Journal of Economics, 107(4), 693-709.

Grossman, S. J., Hart, O. D., 1986. The costs and benefits of ownership: A theory of vertical and lateral integration. Journal of political economy, 94(4), 691-719.

Helpman, E., Melitz, M.J., Yeaple, S.R., 2004. Exporting and FDI with Heterogeneous Firms. American Economic Review, 94(1), 300-16.

Ivus, O., Saggi, K., Park, W., 2016. Patent Protection and the Industrial Composition of Multinational Activity: Evidence from U.S. Multinational Firms. mimeo working paper.

Ivus, O., 2010. Do Stronger Patent Rights Raise High-Tech Exports to the Developing World?. Journal of International Economics, 81(1), 38-47.

Javorcik, B. S., 2004a. The composition of foreign direct investment and protection of intellectual property rights: Evidence from transition economies. European economic review, 48(1), 39-62.

Javorcik, B. S., 2004b. Does foreign direct investment increase the productivity of domestic firms? In search of spillovers through backward linkages.. The American Economic Review, $94(3), 605-627$.

Javorcik, B. S.,Spatareanu, M., 2009. Tough love: do Czech suppliers learn from their relationships with multinationals?. The Scandinavian Journal of Economics. The Scandinavian Journal of Economics, 111(4), 811-833.

Keller, W., Yeaple, S.R., 2013. Gravity in the Knowledge Economy. American Economic Review, forthcoming, 103(4), 55.

Lee, K., Choo, K, Yoon, M., 2016. Comparing the productivity impacts of knowledge spillovers from network and arm's length industries: findings from business groups in Korea. Industrial and Corporate Change, 25(3), 407-427.

Maskus, K. E., Dougherty, S. M., Mertha, A., 2005. Intellectual property rights and economic developement in China, in. Fink, C., Maskus, K. E., Editors. Intellectual property and development: lessons from recent economic research. World Bank. 
Maskus, K. E., Penubarti, M., 1995. How trade-related are intellectual property rights?. Journal of International economics. 39(3), 227-248.

Melitz, M. J., and Redding, S. J., 2014. Heterogeneous Firms and Trade. Handbook of International Economics, 71(6), 227-248.

Melitz, M.J., 2003. The Impact of Trade on Intra-Industry Reallocations and Aggregate Industry Productivity. Econometrica, 71(6), 1695-1725.

Naghavi, A., Spies, J. and Toubal, F., 2015. Intellectual property rights, product complexity and the organization of multinational firms.. Canadian Journal of Economics, 48(3), 881902 .

Naghavi, A.,C. Strozzi, 2015. Intellectual Property Rights, Diasporas, and Domestic Innovation. Journal of International Economics, 96(1), 150-161.

Nunn, N., 2007. Relationship-Specificity, Incomplete Contracts and the Pattern of Trade. Quarterly Journal of Economics, 122(2), 569-600.

Nunn, N., Trefler, D., 2008. The boundaries of the multinational firm: an empirical analysis.. The organization of firms in a global economy, 55-83.

Nunn, N., Trefler, D., 2013. Incomplete Contracts and the Boundaries of the Multinational Firm. Journal of Economic Behavior \& Organization, 94(1), 330-344.

Ottaviano, G., Turrini, A., 2007. Distance and foreign direct investment when contracts are incomplete. Journal of the European Economic Association, 5(4), 796-822.

Park, W. G., 2008. International patent protection: 1960-2005. Research policy, 37(4), 761-766.

Park, W. G.,D. Lippoldt, 2005. International Licensing and the Strengthening of Intellectual Property Rights in Developing Countries during the 1990s. OECD Economic Studies, 40, 7-48.

Pierce, J.R., Schott, P., 2009. A Concordance Between Ten-Digit U.S. Harmonized System Codes and SIC/NAICS Product Classes and Industries. NBER Working Paper, 15548.

Smith, Pamela J., 1999. Are weak patent rights a barrier to US exports?. Journal of International Economics, 48(1), 151-177.

Smith, Pamela J., 2009. Democracy and Foreign Education. American Economic Review, $99(1), 528-543$.

Yang, G., and Maskus, K. E., 2001. Intellectual property rights, licensing, and innovation in an endogenous product-cycle model. Journal of International Economics, 53(1), 169-187. 